\title{
MULTICRITERIA DECISION SUPPORT- APPROACH AND APPLICATION IN THE FIELD OF MATERIALS SCIENCE
}

\author{
Nikolay Tontchev \\ "Todor Kableshkov" University of Transport, Sofia, Bulgaria \\ Zoran Čekerevac \\ Faculty of Business and Industrial Management, "Union” University, Belgrade, Serbia
}

\section{() MESTE NGO}

\begin{abstract}
The research will focus on creating opportunities for prediction of mechanical properties as a function of the chemical composition and the heat treatment parameters taking into account the appropriate boundary conditions.
\end{abstract}

The solutions for predicting properties as a function of the composition and the processing parameters are defined for specific customer requirements. This is accomplished by numerical procedures that determine the optimal composition for a number of criteria with established advantages for the significance of the results. The accuracy of the solution is determined by the reliability of the used experimental data. The actuality of the research of predicting the properties of materials is determined by the fact that the established models are based on computer simulation for building contemporary design tools. The practical results are applicable and they can be used for: a) the design of more efficient compositions in terms of the expensive alloying elements while maintaining the basic properties above a given threshold, b) evaluation of the technological cost of equally applicable technological variants of varying degrees of doping steel, c) determination of a rational representative of a certain class of materials best suited to the requirements previously set (most often controlled properties) among the rest of the class.

Keywords: metallic materials, ferrous alloys, modeling and optimization properties, DSS, multi-criteria decision analysis

\section{INTRODUCTION}

Engineers and experts that implement their projects, they need to use modern approaches to in order to choose materials and design process of the product. With their scientific and practical

The address of the corresponding author: Nikolay Tontchev

㪯= tontchev@vtu.bg work they have to enable the responses to a range of issues related to the modeling and optimization of steel and their technological processes of transformation. As a result of the great number of significant factors, the idea for the application of multicriterial decision support systems is imposed.

Theoretical and practical aspects of multicriterial decision support systems were analyzed by 
various researchers as (Colson, 2000), (Purao, Jain, \& Nazareth, 1999), (Sen, Tan, \& Spencer, 1999). (Zavadskas, 2004) In the area of material sciences, multicriteria decision support approach was used in the last decades in problems of material composition (Tontchev \& Ivanov, 2006), production (Brito, Silva, Botter, \& Medina, 2010), recycling (Spengler, Geldermann, Haehre, Sieverdingbeck, \& Rentz, 1998), as well as in cost optimization (Sarma \& Adeli, 2000), and design (Gedig \& Stiemer, 2006).

In the field of materials science, the processes of changing the structure and the properties of various materials are analyzed. These analyses are driven by the goal to get and accumulate knowledge about them. They define the field of application of appropriate technologies and materials. The emphasis in the process of testing is put on different characteristics of quality, requirements for providing, such as:

- high strength (static and/or dynamic),

- stiffness (E-modulus) and toughness (the material/product);

- high wear resistance and hardness;

- good workability;

- $\quad$ high temperature resistance;

- appropriate cost;

- environmental compatibility and recyclability.

Due to contradictory nature of the properties of metallic materials, optimization tasks do not meet the expected extremes in the same coordinates of the control parameters. The confrontation between the different criteria leads to the formulation of multi-objective problems. They are characterized by the fact that they do not have a single solution. For the solutions of the problem it is necessary to find the Pareto front after which the Decision Maker (DM) must determine good solution for the composition of the alloy and also for its mode of processing. The formulated criteria are directly related to: high performance (functionality) and quality (structural and operational characteristics), as well as high economic efficiency.

An increased requirement for quality production of materials also implies the need to use advanced tools for analysis and modeling. The automated design of compositions and modes of treatment is possible to implement with modern computing facilities.
The development of methods and software support the design of configurations and the modes of the alloy treatments. The requirements for the materials, already mentioned as confronted with the properties and behavior under real operating conditions, however, are not fully identified.

By multicriteria optimization it is possible to reach a compromise between the conflicting characteristics of the trend change. Paretooptimal solution (according Pareto-optimal management) has the following property: any deviation from it in order to improve one or more criteria leads to a deterioration of at least one or more of the other criteria.

In Bulgaria, modeling and optimization of technological processes has begun its development from the early eighties of the previous century. Most of all were developed methods for processes modeling in the fields of chemical engineering, metallurgy and casting, etc. ((Novik \& Arsov, 1981), (Stoyanov, 1993), (Vuchkov \& Stoyanov, 1980), (Vuchkov I. , 1984), (Djonov, Angelov, \& Petrov, 1995)).

Generalized representative results about the achievements in the field of optimization of technological processes are presented in Tellalyan's PhD thesis (Methods and algorithms for optimization of processes with complex objective functions, 1985), Stoyanov's dissertation (Methods and algorithms for fast convergence, 1990), and Vuchkov (Experimental investigation and identification, 1990).

The purpose of this work is to propose an approach with operational capabilities enhancing and specifically enhancing the reliability of alloy steels from a given class, using the technique of modeling the properties via the composition and the mode of processing. The suggested approach, developed at the level of methodology, must be also transferred to the related technological cost of blanks used in metalworking.

The achievement of the objective of this work should include solutions for the following main problems:

Creation of a nonlinear analytical model to control the properties of steels depending on the chemical composition in the heat-treated condition. This means a research of the 
possibility to predict properties of the blank using regression analysis tools. For this purpose it is necessary to create a procedure and also software for analysis of the studied parameters;

- Preparation of some of the achieved, practically oriented results for implementation in industry.

\section{ADAPTATION OF THE METHOD IN HANDLING THRUST CONSTRAINTS FOR MULTICRITERIA OPTIMIZATION}

The main steps in solving the problem of design and optimization, which are applicable for material selection and design of technology for processing, are as follows:

1. Defining of a set of properties and determining the interconnections between the elements of the generalized multicriteria model;
2. Collecting and processing the available information (quantitative and qualitative);

3. Determination of the control parameters, the variation, which leads to substantial modification of the parameters of quality (the criteria);

4. Formulation of the problem of system management for the material selection and the processing mode;

5. Creation of a set of models defining the relationship between the control parameters and the criteria of quality;

6. Solving the multicriteria optimization problem and decision making for the design process.

Fig. 1 shows a sample surface in response to a modification of the indicator of quality, depending on the value of inputs' parameters.
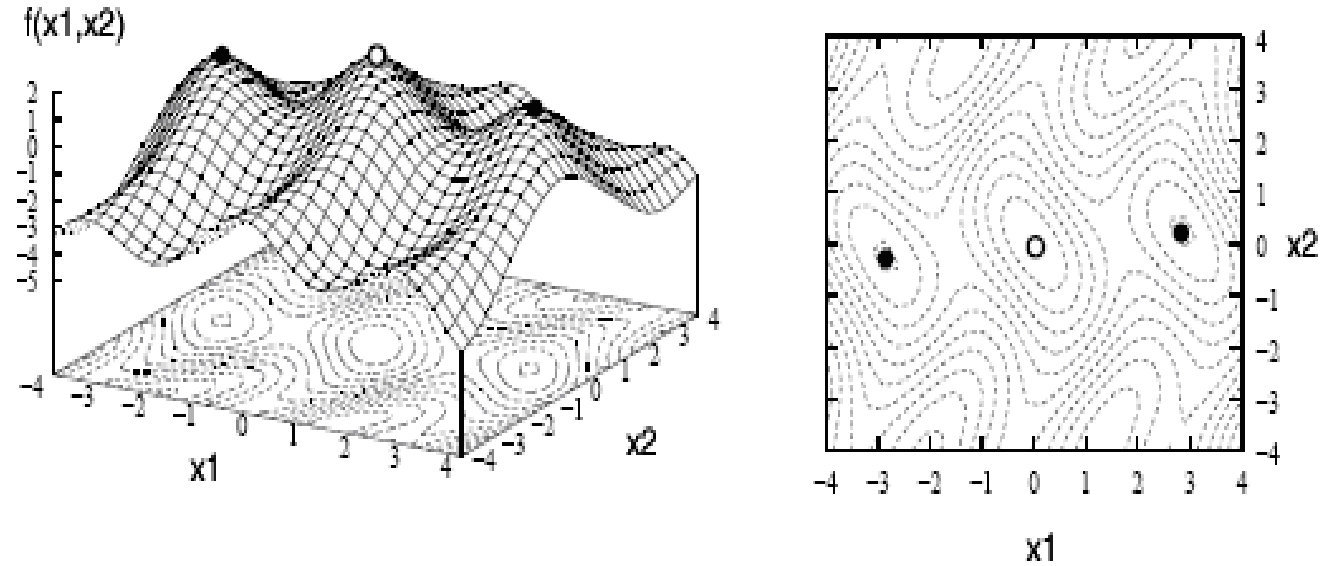

Fig. 1 Graphic interpretation of a single-criteria optimization problem with two factors of variation It is accepted that such surfaces must be analyzed graphically by contour diagrams defined by equilevel lines (the lines of constant levels). Thus it is possible graphically to define the coordinates of the values of the process parameters, which occur in local or global maxima and minima of the target parameter.

In order to proceed with this analysis, it is necessary to perform a discretization of the variables in the plane of the process parameters. Discretization is performed in the range of variation for each variable with a definite step. The accuracy of the defined solutions depends on the step size.

Fig. 2 shows an exemplary discretization $10 \times 10$ in the plane of the control parameters.

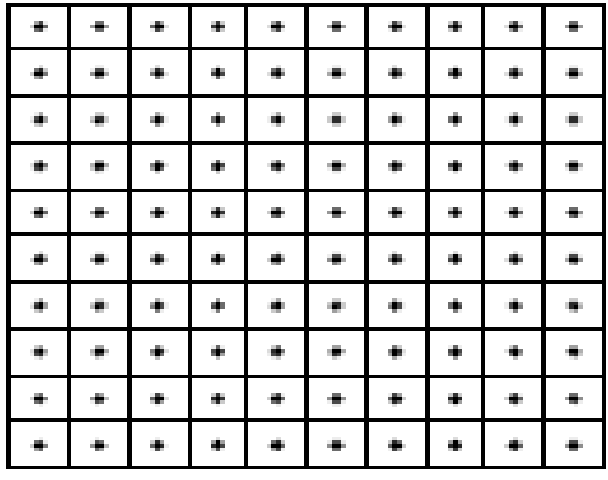

Fig. 2 Arrangement of a $10 \times 10$ sample in the plane of variables

Organization of discretization in the vicinity of the cell [i, j] may be carried out as follows: 


\begin{tabular}{|c|l|l|}
\hline$i-1, j+1$ & $i, j+1$ & $i+1, j+1$ \\
\hline$i-1, \quad j$ & $i, \quad j$ & $i+1, \quad j$ \\
\hline$i-1, j-1$ & $i, j-1$ & $i+1, j-1$ \\
\hline
\end{tabular}

For the implemented discretization it is possible to calculate the values of the quality indicators, so through this sequence a discrete contour plot is constructed. The tool, which crawls through the discrete plane of technology parameters, is called a "magnifying glass". The movement of the magnifying glass in the plane of the process parameters determines the relationship between them and the value of the studied parameter of the quality tests.

Digitized contour diagrams can be represented in a convenient, user-friendly, form of the decision maker. The performance is related to staining in different colors for different areas, bounded by the contour lines. Different colors are projected in the plane of analysis by scanning the surface of the response to multiple (up to six) planes. An essential feature of this presentation is the different range of variation for certain values of the target parameter. Therefore, the geometric representation of the digitized image will depend on the location of the plains along the axis of criteria (indicators of quality). The corresponding color on the discrete contour plot is directly related to the value of the indicator of the quality.

Fig. 3 presents a discrete contour diagram of an example of the surface for the parameter of quality with five scanning, restrictive, planes in respective colors with two factors of variation. If the first, the second and the third planes occupy the location of the fourth, then the image will be simplified (the discrete contour plot will be only in two colors), thus localizing the area of the solutions to the area is marked by five. This procedure is performed in the case that there is a search of the maximal values of the goal function.

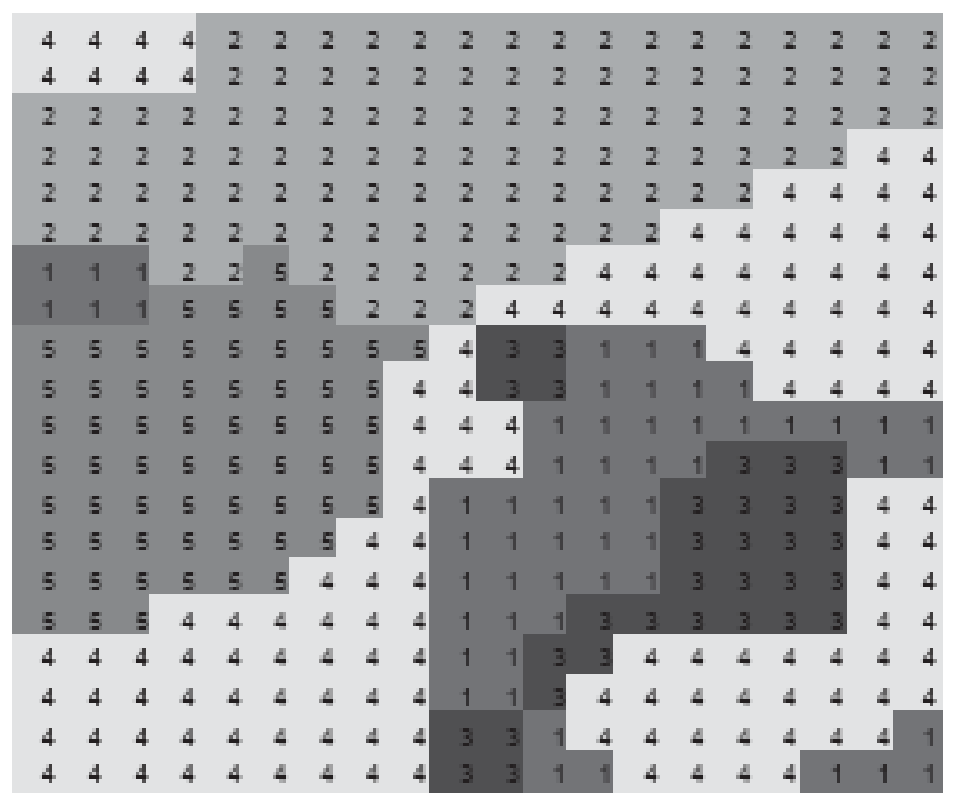

Fig. 3 Example of two-dimensional discrete contour plot with five scanning planes

The values of the examined parameter in zone five differ in size. The fixed area defined already from the fifth plane can therefore be scanned again for example by four planes - an act leading to the localization of the maximum / minimum also by the described procedure. So, moving the five planes, the decision maker can analyze the goal function in the plane of analysis and he/she can recommend a combination of control parameters. This graphical approach is adapted for solving problems for analysis and optimization in the field of materials science to four factors of change.

An exemplary presentation of images supporting the analysis of the four-factor space for two successive iterations is shown also in Fig. 4.

The image is defined on one side by means of the coefficients of the regression model, and on the other by the level of the thrusting constraints. To carry out an analysis by color arrangement it is necessary to normalize the value of the goal parameter in the space of the analysis. 


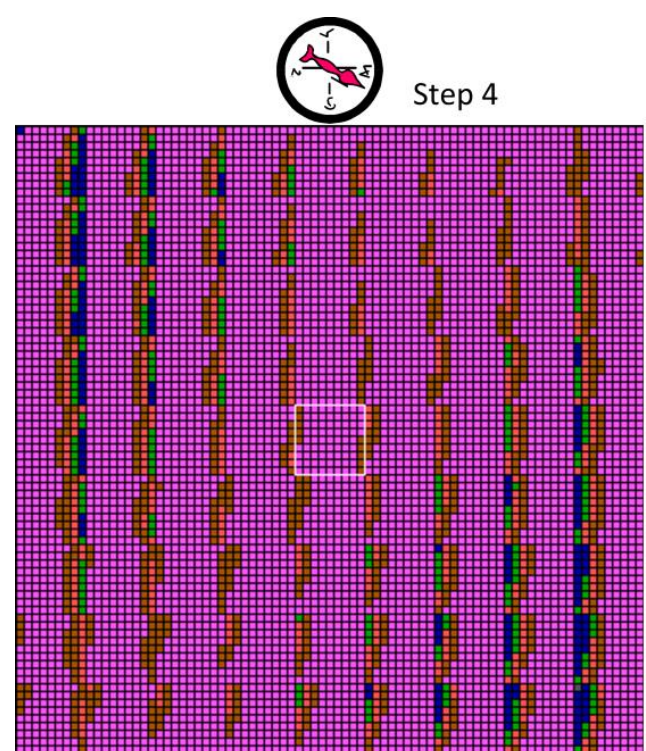

$\begin{array}{lccccc}\mathrm{Y}[1] \text { between } & 0 & . & 30 & \% \\ \mathrm{Y}[2] \text { between } & 30 & . & 40 & \% \\ \mathrm{Y}[3] \text { between } & 40 & . & 50 & \% \\ \mathrm{Y}[4] \text { between } & 50 & . . & 60 & \% \\ \mathrm{Y}[5] \text { between } & 60 & . . & 100 & \%\end{array}$

$$
\begin{array}{ll}
\mathrm{a}_{1}=0.4325 & \mathrm{a}_{6}=-1.196 \\
\mathrm{a}_{2}=-0.008248 & \mathrm{a}_{7}=-0.259
\end{array}
$$$$
\mathrm{a}_{3}=-0.228915 \quad \mathrm{a}_{8}=2.9977
$$$$
\mathrm{a}_{4}=0.033695 \quad \mathrm{a}_{9}=0.15847
$$

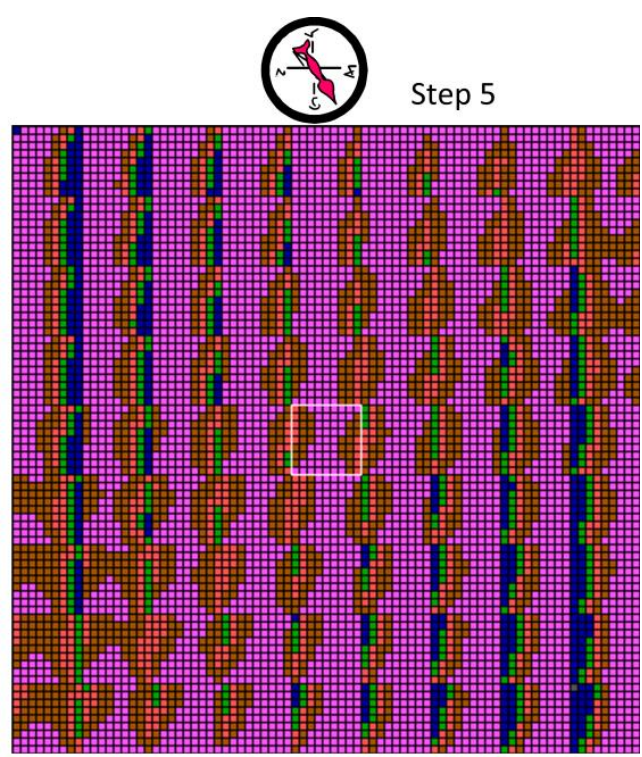

$$
\mathrm{a}_{11}=2.15432
$$

$\mathrm{a}_{12}=1.01693$

$\mathrm{a}_{13}=-1.95535$

$\mathrm{a}_{14}=-0.944752$

$\mathrm{a}_{15}=0.744787$

$$
\begin{gathered}
a_{5}=0.003165 a_{10}=0.61596 \quad a_{15}=0.744787 \\
Y\left(x_{1}, x_{2}, x_{3}, x_{4}\right)=a_{1}+a_{2} \cdot x_{1}+a_{3} \cdot x_{2}+a_{4} \cdot x_{3}+a_{5} \cdot x_{4}+a_{6} \cdot x_{1}{ }^{2}+a_{7} \cdot x_{1} \cdot x_{2}+a_{8} \cdot x_{1} \cdot x_{3}+a_{9} \cdot x_{1} \cdot x_{4}+ \\
+a_{10} \cdot x_{2}{ }^{2}+a_{11} \cdot x_{2} \cdot x_{3}+a_{12} \cdot x_{2} \cdot x_{4}+a_{13} \cdot x_{3}{ }^{2}+a_{14} \cdot x_{3} \cdot x_{4}+a_{15} \cdot x_{4}{ }^{2}
\end{gathered}
$$

Fig. 4 Images for analysis of four-factorial space of the described regression model

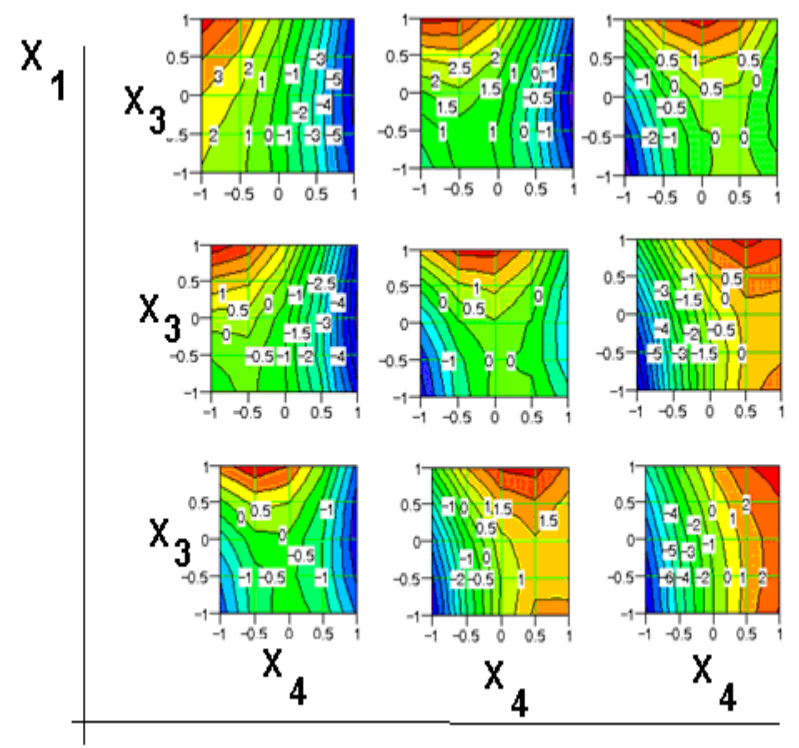

\section{$x_{2}$}

Fig. 5 Presentation of the four factors MCAD space without normalizing the values of the target parameter

Fig. 5 shows an image of the model from Fig.4, The analysis together with the normalization and realized with MCAD; the steps $X_{1}$ and $X_{2}$ are equal to 1 each, and $X_{3}$ and $X_{4}$ to -0.5 in the the thrusting constraints makes it easy to range of $[1,1]$ for the four variables. 
where the index of quality accepts a precisely defined value.

One example in this respect is shown in Fig. 6 where the research value in the range between

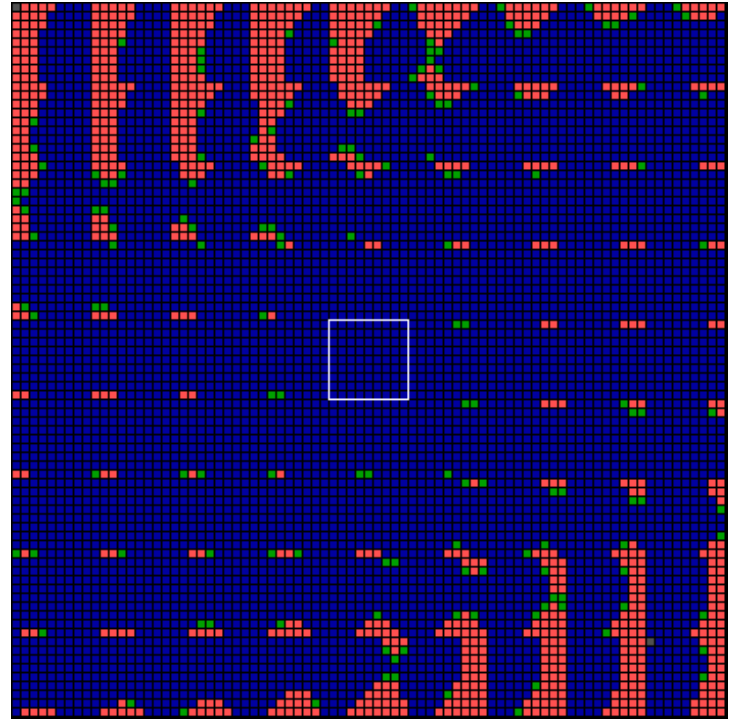

$80-81 \%$ is marked with the appropriate color (green) encountered in the field for analysis.

\begin{tabular}{|c|c|c|c|c|}
\hline $\mathrm{Y}[1]$ & 0 &.. & 80 & $\%$ \\
\hline $\mathrm{Y}[2]$ & 80 &.. & 81 & $\%$ \\
\hline $\mathrm{Y}[3]$ & 81 &.. & 100 & $\%$ \\
\hline
\end{tabular}

Fig. 6 Presentation of the approach as a means for determination of effective solutions for analysis of a single goal parameter

If the value in this range satisfies the person assisting the decision making in the case (as seen from fig.6), he/she has a wide selection to determine a more energy-efficient solution. The reason for this is that the decisions of the research space are spread almost all over the area. These fixed solutions have different changes also from an economic aspect.

Another feature of the approach with normalization and thrusting constraints is to determine the search direction. The second largest area, displayed on Fig. 6, represents the values above $81 \%$.

\section{APPLICATION OF MULTICRITERIA}

APPROACH FOR THE SELECTION OF MATERIALS AND THE MODE OF TREATMENT FROM A CLASS OF HEAT RESISTANT STEELS

Operational durability, reliability and competitiveness of industrial products depend on the used materials and also on the applied various (mechanical, physical, chemical, etc.) impacts on them. Especially significant contribution to the achievement of the required quality of the parts and the equipment belongs to the preliminary and the final heat treatment and chemical-thermal processing. Pre-heat treatment before nitriding aims at achieving certain mechanical properties of the core (strength, hardness, toughness), minimal internal stresses, enhanced successive mechanical processing, small grains and other properties (heat resistance, structural homogeneity, etc.). Only after properly selected and conducted preliminary heat treatment nitrided layer can reach its best characteristics - hardness, wear resistance, fatigue strength, heat resistance, high resistance against brittle fracture, etc. Also in this case the optimal values of the target parameters are obtained by different combinations of the input parameters, so in the process of optimization practically it is impossible to perform a simultaneous maximization of all output parameters.

Here will be illustrated the approach in determining the steel grade and the mode for its treatment, providing the highest lifetime operational durability, and taking into account the energy consumption of the technology. The methodology for saving energy and/or materials is based on multicriteria optimization using regression models describing the dependence on the mechanical properties of the parameters of the nitriding mode. It is based on the principle 
that multicriteria problem has to be solved first. The result is a set of close Pareto vectors differing one from another energetically or in relation to the amounts of expensive alloying components. Energetically the most favorable, or material-effective solution is prescribed after the verification of the energy consumption and/or the material consumption.

The example set of steels for research are typical representatives of alloy(ed) tool steels for operation in hot environments and in this role it is very important for the users to identify modes of thermal and chemical-thermal treatments that simultaneously ensure relatively best micro hardness, toughness of destruction and durability. Table 1 contains the chemical composition of steels of this type. Table 2 shows their basic strength and plastic characteristics.

The necessary factors for the realization of an optimization problem are the following:

\subsection{Object for optimization.}

For the example the object for optimization are the properties of tool steels for hot working (micro hardness, toughness of destruction and wear resistance) in the process of ion nitriding.

Table 1 Chemical composition of steel from the class of scope, [\%](GOST, Tool steel, 2010)

\begin{tabular}{|c|c|c|c|c|c|c|c|}
\hline Steel & $\mathbf{C}$ & $\mathbf{S i}$ & $\mathbf{M n}$ & $\mathbf{C r}$ & $\mathbf{M o}$ & $\mathbf{W}$ & $\mathbf{V}$ \\
\hline 4H5MFS & $0.32-0.4$ & $0.9-1.2$ & $0.2-0.5$ & $4.5-5.5$ & $1.2-1.5$ & - & $0.3-0.5$ \\
\hline 3H3M3F & $0.27-0.34$ & $0.1-0.4$ & $0.2-0.5$ & $2.8-3.5$ & $2.5-3.0$ & - & $0.4-0.6$ \\
\hline 3H2V8F & $0.3-0.4$ & $0.15-0.4$ & $0.15-0.4$ & $2.2-2.7$ & Up to 0.5 & $7.5-8.5$ & $0.2-0.5$ \\
\hline
\end{tabular}

Table 2 Characteristics of the steels in scope (GOST, 2007-2013)

\begin{tabular}{|c|c|c|c|c|c|}
\hline Steel & $\begin{array}{c}\text { Yield } \\
\text { strength } \\
\mathbf{R m} \\
{[\mathrm{MPa}]}\end{array}$ & $\begin{array}{c}\text { Tensile } \\
\text { strength } \\
\mathbf{R e} \\
{[\mathrm{MPa}]}\end{array}$ & $\begin{array}{c}\text { Elongation } \\
{[\%]}\end{array}$ & $\begin{array}{c}\text { Contraction } \\
\mathbf{Z} \\
{[\%]}\end{array}$ & $\begin{array}{c}\text { Impact } \\
\text { strength } \\
\mathbf{K C U} \\
{\left[\mathrm{kJ} / \mathrm{m}^{2}\right]}\end{array}$ \\
\hline $4 \mathrm{H} 5 \mathrm{MFS}$ & 1750 & 1480 & - & - & 570 \\
\hline 3H3M3F & 1670 & 1470 & - & 50 & 220 \\
\hline 3H2V8F & 1530 & 1390 & 12 & 36 & 200 \\
\hline
\end{tabular}

\subsection{Manageability of the object}

In order to ensure the management of the object, there must be control parameters (degrees of freedom) that are being modified independently from each other. Table 3 indicated the range of variation of the ruling parameters for the mode of thermal and chemicothermal processing. With the variation of the technological factors on the process a planned experiment is run which resulted in the output models checked for adequacy. Zyumbilevin's dissertation (Effect of low temperature plasma nitriding on the properties of tool steels for hot working, 1992) has defined the relationship between the goal parameters and the technological factors of the modes for processing.
To determine the nitriding modes there have been used mathematical and statistical methods of the planned experiment. A characteristic of this approach is that a compulsory change of input factors is performed within certain limits. Minimum number of trials and simultaneous adjusting of all factors is used. The main problem is reduced to determining the mathematical form of the research, which can be expressed in the given process.

Based on bibliography data and preliminary experiments, the following input (control) factors are defined in Zyumbilev A. (1992): the nitriding temperature, the pressure, the duration of the process, and the temperature of tempering. The following requirements are satisfied during the selection of these factors: independence from 
each other, compatibility between them and the ability to drive them.

Table 3 Variation range of the input parameters

\begin{tabular}{|l|c|c|c|c|}
\hline \multicolumn{1}{|c|}{ Factors } & $\begin{array}{c}\mathbf{T}_{\mathbf{a z}} \\
{\left[{ }^{\circ} \mathrm{C}\right]}\end{array}$ & $\begin{array}{c}\mathbf{P} \\
{[\mathrm{Pa}]}\end{array}$ & $\begin{array}{c}\tau \\
{[\mathrm{h}]}\end{array}$ & $\begin{array}{c}\mathbf{T}_{\text {otvr. }} \\
{\left[{ }^{\circ} \mathrm{C}\right]}\end{array}$ \\
\cline { 2 - 5 } Levels X & $\mathrm{X}_{1}$ & $\mathrm{X}_{2}$ & $\mathrm{X}_{3}$ & $\mathrm{X}_{4}$ \\
\hline Zero level (0) & 530 & 300 & 7 & 650 \\
Interval of variation & 20 & 150 & 3 & 50 \\
Upper level (+l) & 550 & 450 & 10 & 700 \\
Lower level (-I) & 510 & 150 & 4 & 600 \\
\hline
\end{tabular}

Based on the influence of various factors on the nitriding and the objectives pursued, the following parameters were selected for optimization (matching factors): maximal micro-hardness of the layer $\mathrm{H} \mu \mathrm{V}$, relative degree of wear $\mathrm{K}_{v}$ and toughness of destruction $\mathrm{K}_{1 \mathrm{c}}\left(\mathrm{K}_{\mathrm{q}}\right)$.

Selected in this way, the factors and intervals are used to design experiments also on the basis of a plan of the various combinations of processingmode parameters with which the experiments were conducted. In order to reduce the errors it is recommended that every attempt is done twice and the combinations of zero-level factors five times. All samples were ion nitrided in an installation of type ION-20 (Anon, 2013). The impregnation gas during nitriding in glow discharge was gaseous ammonia. After nitriding the samples were cooled in air. About ion nitriding is written in many papers, e.g. (Čekerevac, 1982) or (Kopelovich, 2012)

\subsection{Criterion for optimality}

This is a numerical index which values the object of optimization. It may be technical, technological, economic, and mixed technoeconomic. For the defined example, the criteria for optimality are technological and techno- economic. The best value on the criterion of optimality is called optimum or extreme. In this example, it is necessary to determine the technological parameters, thermal and chemicalthermal processing providing simultaneous maximal micro-hardness and toughness of destruction and minimal wear.

\subsection{Optimization method.}

It is the most important prerequisite for the solution of optimization problems, because it reflects the principled nature of the search process for the best result regardless of the character of the object for optimization and the set goal.

The choice of a particular method is determined by requirements and by the nature of the object and also by the correct definition of the optimization problem.

In the example the criterion of optimality for technological objects is expressed with three objective functions. The optimization problem boils down to monocriterial, which needs an appropriate algorithm. In principle, the optimization is carried out under direct experimentation with the object of the scheme: control action - the result - a new control action. In practice, however, the optimization research is carried out with the object or the system represented by a mathematical model.

Mathematical models allow numerical experiments for the most economical research of the influence of the control parameters on the performance of the existing system or the criterion of efficiency of design.

For this example, below is given the relation between the technological factors and the goal examples. Their methodologies are given in Zyumbilev A.(1992).

$$
\begin{aligned}
& \text { For steel 4H5MFS } \\
& \mathrm{HV}_{0 . \mathrm{I}}=11914.4+254.13 \mathrm{X}_{1}-143.65 \mathrm{X}_{2}+134.44 \mathrm{X}_{3}-274,03 \mathrm{X}_{4}-51.50 \mathrm{X}_{1}^{2}+248.75 \mathrm{X}_{1} \mathrm{X}_{2}-88.75 \mathrm{X}_{1} \mathrm{X}_{3}- \\
& \text { 136.25 } X_{1} X_{4}-624.00 X_{2}^{2}-301.25 X_{2} X_{3}+76.25 X_{2} X_{4}+194.00 X_{3}^{2}-36.25 X_{3} X_{4}-144.00 X_{4}^{2} \\
& \mathrm{~K}_{\mathrm{Q}}=\mathrm{Y}_{4}=83.2-1.52 \mathrm{X}_{1}+5.3 \mathrm{X}_{2}+3.77 \mathrm{X}_{3}+1.89 \mathrm{X}_{4}-3.75 \mathrm{X}_{12}+4.63 \mathrm{X}_{1} \mathrm{X}_{2}-4.00 \mathrm{X}_{2}^{2}-3.5 \mathrm{X}_{4}^{2} \\
& K_{v}=0.4020-0.0828 X_{1}+0.0033 X_{2}-0.0523 X_{3}-0.0008 X_{4}+0.0037 X_{1}^{2}+0.0106 X_{1} X_{2}+0.0244 X_{1} X_{3} \\
& 0.0006 X_{1} X_{4}+0.0087 X_{2}^{2}-0.0469 X_{2} X_{3}+0.0031 X_{2} X_{4}+0.0237 X_{3}+0.0093 X_{3} X_{4}+0.0512 X_{4}^{2}
\end{aligned}
$$


For steel ZHZMZF

$$
\begin{aligned}
& \mathrm{HV}_{0.1}=11527.2-129.5 \mathrm{X}_{1}+150.41 \mathrm{X}_{2}-292.02 \mathrm{X}_{4}+87.50 \mathrm{X}_{1} \mathrm{X}_{2}-62.50 \mathrm{X}_{1} \mathrm{X}_{3}-75 \mathrm{X}_{2} \mathrm{X}_{3}-137.50 \mathrm{X}_{2} \mathrm{X}_{4}-234.5 \mathrm{X}_{3}^{2} \\
& 137.50 \mathrm{X}_{3} \mathrm{X}_{4}-194.50 \mathrm{X}_{4}^{2} \\
& K_{Q}=Y_{8}=74.76-2.24 X_{1}-1.76 X_{2}-0.52 X_{3}+19.06 X_{4}-16.1 X_{1}^{2}+2.13 X_{1} X_{2}-2.5 X_{1} X_{3}-X_{1} X_{4} \\
& 17.35 \mathrm{X}_{2}^{2}+1.25 \mathrm{X}_{2} \mathrm{X}_{3}-2.25 \mathrm{X}_{2} \mathrm{X}_{4}+14.65 \mathrm{X}_{3}{ }^{2+} 0.88 \mathrm{X}_{3} \mathrm{X}_{4}-8.85 \mathrm{X}_{4}{ }^{2} \\
& \mathrm{~K}_{\mathrm{V}}=0.3898-0.0786 \mathrm{X}_{1}-0.0099 \mathrm{X}_{2}- \\
& 0.0494 X_{3}+0.0151 X_{4}+0.0307 X_{1}^{2}+0.0131 X_{1} X_{2}+0.0044 X_{1} X_{3}+0.0157 X_{1} X_{4}+0.0257 X_{2}^{2}- \\
& 0.0494 X_{2} X_{3}+0.0243 X_{2} X_{4}+0.0107 X_{3}^{2}-0.0218 X_{3} X_{4}+0.0457 X_{4}^{2}
\end{aligned}
$$

\section{For steel ZH2V8F}

$$
\begin{aligned}
& \mathrm{HV}_{0 . \mathrm{I}}=11074.8-92.33 \mathrm{X}_{2}+97.99 \mathrm{X}_{3}-514.46 \mathrm{X}_{4}+117.00 \mathrm{X}_{1}^{2}+86.25 \mathrm{X}_{1} \mathrm{X}_{3}+311.25 \mathrm{X}_{1} \mathrm{X}_{4}-93.00 \mathrm{X}_{2}^{2}- \\
& 273.75 \mathrm{X}_{2} \mathrm{X}_{3}-173.75 \mathrm{X}_{3} \mathrm{X}_{4}-85.50 \mathrm{X}_{4}^{2} \\
& \mathrm{~K}_{\mathrm{Q}}=\mathrm{Y}_{12}=40.52-9.3 \mathrm{X}_{1}-1.8 \mathrm{X}_{2}-3.49 \mathrm{X}_{3}+13.49 \mathrm{X}_{4}-2.7 \mathrm{X}_{1}^{2}+0.625 \mathrm{X}_{1} \mathrm{X}_{2}-5.25 \mathrm{X}_{1} \mathrm{X}_{4}-2.20 \mathrm{X}_{2}^{2}+0.125 \mathrm{X}_{2} \mathrm{X}_{3}- \\
& 2.95 \mathrm{X}_{3}-3.38 \mathrm{X}_{3} \mathrm{X}_{4}+13.05 \mathrm{X}_{4}^{2} \\
& K_{V}=Y_{14}=0.3804-0.0804 X_{1}-0.0076 X_{2}-0.0504 X_{3}+0.0300 X_{4}+0.0156 X_{1}^{2}+0.0050 X_{1} X_{2}- \\
& 0.0025 X_{1} X_{3}+0.0037 X_{1} X_{4}+0.385 X_{2}^{2}-0.054 X_{2} X_{4}-0.029 X_{3}^{2}-0.037 X_{3} X_{4}+0.059 X_{4}^{2}
\end{aligned}
$$

The set of points satisfying the constraints is called the set of acceptable solutions for the goal function $\mathrm{Q}(\mathrm{x})$ or, for brevity, the eligible

\begin{tabular}{|c|c|c|c|c|c|c|c|}
\hline \multirow{2}{*}{$\begin{array}{l}\text { Para- } \\
\text { meters }\end{array}$} & \multicolumn{2}{|c|}{ 4H5MFS } & \multicolumn{3}{|c|}{ ZH3M3F } & \multicolumn{2}{|c|}{ ZH2V8F } \\
\hline & $\# 1$ & $\# 2 \equiv \# 3$ & $\# 1$ & \#2 & \#3 & $\# 1$ & $\# 2 \equiv \# 3$ \\
\hline$X_{1}$ & 0.5 & 1 & -0.25 & 0.25 & 0 & -1 & -1 \\
\hline$X_{2}$ & 0.25 & 0.25 & 0.0 & 0.5 & 0.5 & -0.25 & -0.25 \\
\hline$X_{3}$ & 0.75 & 0.75 & 0.25 & 1 & 1 & 0 & 1 \\
\hline$X_{4}$ & -0.5 & -0.25 & 0 & -0.25 & -0.25 & -1 & -1 \\
\hline $\mathrm{Hv}$ & 12060 & 12110 & 11550 & 11410 & 11440 & 11950 & 12200 \\
\hline $\mathrm{K}_{\mathrm{Q}}$ & 84.16 & 82.29 & 75.25 & 77.18 & 79.04 & 41.89 & 38.80 \\
\hline $\mathrm{K}_{\mathrm{V}}$ & 0.348 & 0.312 & 0.399 & 0.313 & 0.329 & 0.523 & 0.483 \\
\hline
\end{tabular}
area.

The algorithm for solving the optimization problem is a sequence of logical and computational actions that achieve the best result under these conditions. The most important requirements for the algorithms are the ones for convergence and versatility.

In this approach, the following results have been obtained for the mechanical properties of the investigated steels in appropriate modes of processing.

Table 4 Optimal values of the input and output parameters

The results listed in Table 4 are derived for coded values of the factors due to the fact that they are determined by the regression models in this way. The values of the target parameters in the Table 4 can be normalized respectively to the smallest and largest values of the considered feature of the class.
As this normalization is common for the three steels and through it, it is possible to range the optimal values of the parameters. This is implemented in Fig. 7. According to the realized ranking it is possible to determine the final decision at the same time with the three goal parameters. 


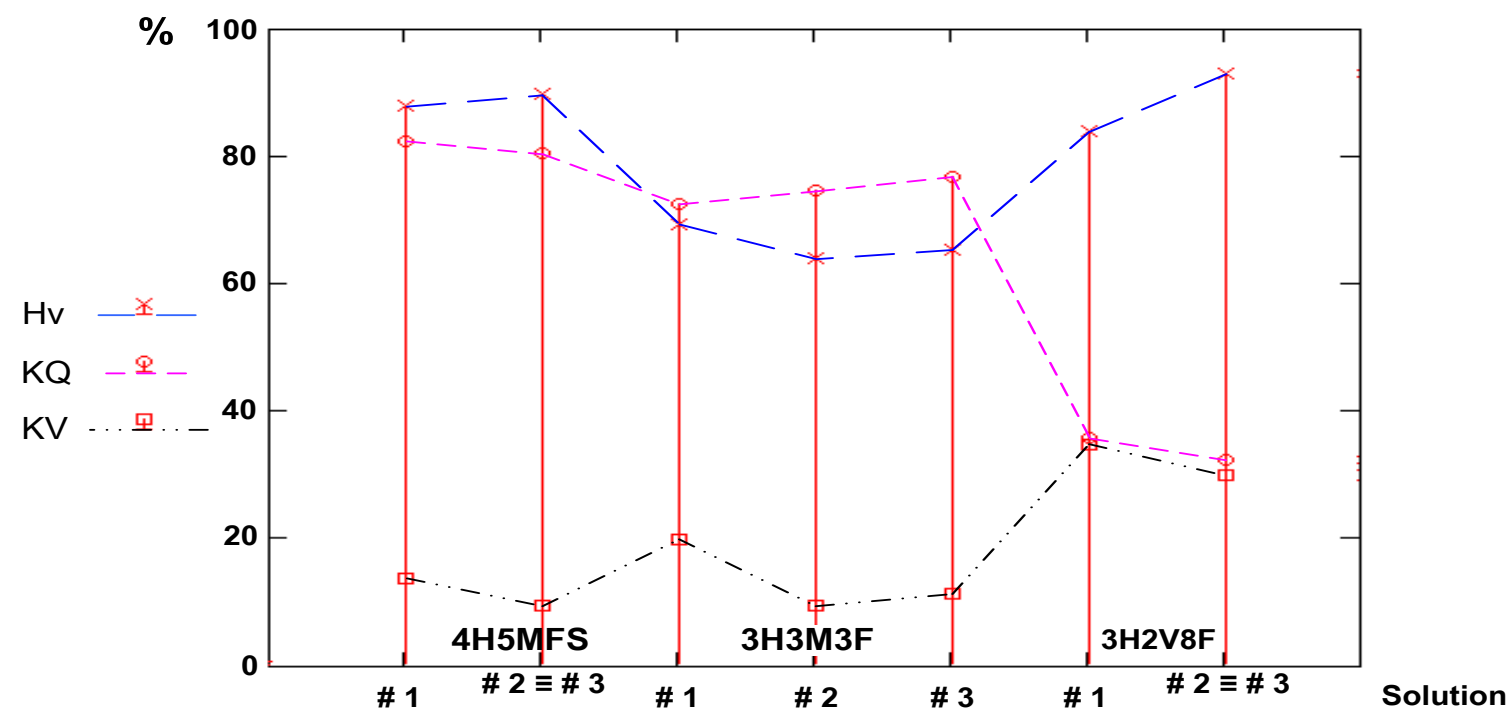

Fig. 7 Graphic interpretation of a comparative research of the multicriteria problem in the class of heat-resistant steels

The relative power consumption of the process for ion nitriding (Tonchev, 2011) is:

$$
Q\left(X_{1}, X_{2}\right)=1.13+0.0837 X_{1}+0.0563 X_{2}+0.008 X_{1}^{2}-0.0176 X_{1} X_{2}-0.0123 X_{2}^{2}
$$

\section{CONCLUSIONS}

Based on the proposed approach to the problem of selection of technology solutions, taking into account the information assurance, procedures have been developed to search for the relevant mode, supplementing the archives of technological solutions.

The joint analysis of Table 4, Fig. 7 together with the expended power, determines decision \# 1 of steel $4 \mathrm{H} 5 \mathrm{MFS}$ as the most effective of the class of heat-resistant steels with corresponding treatment. An approach based on the method described above selects a representative of a given class to meet the preset requirements.

The search and the evaluation of the effective solutions allow the cost reduction of technological reengineering of production, in order to ensure the quality of the planned production and shorten the terms of receipt of the product.

\section{ACKNOWLEDGMENTS}

This work was partially supported by the Bulgarian National Science Fund under the Project No DDVU 02/11 "Characteristic modeling and composition optimization of iron-base alloys used in machinebuilding industry"

\section{WORKS CITED}

Anon. (2013). ION-20 Instalations for Ion Nitriding and Carbonitriding. Retrieved from Alibaba: http://www.alibaba.com/countrysearch/BG/installation-for-ion-nitriding.html

Brito, T. B., Silva, C. R., Botter, R. C., \& Medina, A. C. (2010). DISCRETE EVENT SIMULATION COMBINED WITH MULTI-CRITERIA DECISION ANALYSIS APPLIED TO STEEL PLANT LOGISTICS SYSTEM PLANNING. Proceedings of the 2010 Winter Simulation Conference (pp. 2126-2137). IEEE. Retrieved from http://www.informs-sim.org/wsc10papers/196.pdf

Čekerevac, Z. (1982). Ionian plasma nitrization. Beograd: Vojnotehnicki Institut KoV.

Colson, G. (2000). The OR's prize winner and software ARGOS: how a multijudge and multicriteria ranking GDSS helps a jury to attribute a scientific award. Computers \& Operational Research, 27(7-8), 741-755.

Djonov, T., Angelov, I., \& Petrov, M. (1995). Mathematical simulation and optimization of mechanical characteristics of steels. Gabrovo. 
Gedig, M., \& Stiemer, S. (2006). Decision Tools for the Engineering of steel structures. Electronic Journal of Structural Engineering(6), 19-39. Retrieved from http://www.ejse.org/Archives/Fulltext/2006/200604.pdf

GOST. (2007-2013, 10 06). Catalog product. Retrieved from Electrovek Steel: http://www.evek.rs/grade-list-a-4kh5mfs.html?device=mobile

GOST. (2010). Tool steel. Retrieved 10 06, 2013, from AlfaTech: http://www.atsteels.com/stalnarzedziowa-stal-stopowa-do-pracy-na-goraco-wcl.html

Kopelovich, D. (2012, 05 31). Ion nitriding. Retrieved from SubsTech: http://www.substech.com/dokuwiki/doku.php?id=ion_nitriding

Novik, F., \& Arsov, J. (1981). Planning of the experiment in metal technology. Sofia: Technika.

Purao, S., Jain, H., \& Nazareth, D. (1999). Supporting decision making in combinatorially explosive multicriteria situations. Decision Suport Systems, 26(3), 225-247.

Sarma, K., \& Adeli, H. (2000). Fuzzy Discrete Multicriteria Cost Optimization of Steel Structures. Struct. Eng., 126(11), 1339-1347. Retrieved from http://ascelibrary.org/doi/abs/10.1061/\%28ASCE\%2907339445\%282000\%29126\%3A11\%281339\%29

Sen, P., Tan, J., \& Spencer, D. (1999). An integrated probabilistic risk analysis decision support methodology for systems with multiple state variables. Reliability Engineering \& System Safety, 73-87.

Spengler, T., Geldermann, J., Haehre, S., Sieverdingbeck, A., \& Rentz, O. (1998). Development of a multiple criteria based decision support system for environmental assessment of recycling measures in the iron and steel making industry. Journal of cleaner Production, 6(1), 37-52. Retrieved from http://www.sciencedirect.com/science/article/pii/S0959652697000486

Stoyanov, S. (1990). Methods and algorithms for fast convergence. Sofia: Thesis for DSc, Chemical Technology and Metallurgy.

Stoyanov, S. (1993). Optimization Process. Sofia: Tehnika.

Tellalyan, J. K. (1985). Methods and algorithms for optimization of processes with complex objective functions. Sofia: UCTM - PhD thesis.

Tonchev, N. (2011). The decision to optimum selection of material and technology of processing of a class tool steels, hot work. Akademic journal Mechanics Transport Communication, Special publication, XX International Conference "Transport 2011"(3), Article No. 623.

Tontchev, N., \& Ivanov, S. (2006). Method for solving multiple criteria decision making (MCDM) problems and decision support system. Intelligent Systems - 3rd International IEEE Conference (pp. 126-129). London: IEEE Conference Publications. doi:Intelligent Systems, 2006 3rd International IEEE Conference

Vuchkov, I. (1984). Software for statistical modeling and optimization of multivariable sites. Sofia: Tehnika.

Vuchkov, I. (1990). Experimental investigation and identification. Sofia: Tehnika.

Vuchkov, I., \& Stoyanov, S. (1980). Mathematical modeling and optimization of process units. Sofia: Engineering.

Zavadskas, E. K. (2004). A multiple criteria decision support web-based systems for facilities management. Internet and Enterprise Management, 1-15. Retrieved from http://citeseerx.ist.psu.edu/viewdoc/download?doi=10.1.1.102.5595\&rep=rep1\&type=pdf

Zyumbilev, A. (1992). Effect of low temperature plasma nitriding on the properties of tool steels for hot working. Sofia: Dissertation.

Received for publication:

Revision received:

Accepted for publication:
03.10 .2013

05.11 .2013

02.12 .2013 


\section{How to cite this article?}

Style - APA Sixth Edition:

Tontchev, N., \& Čekerevac, Z. (2014, 01 15). Multicriteria decision support-approach and application in the field of materials science. (Z. Čekerevac, Ed.) MEST Journal, 2(1), 18-29. doi:10.12709/mest.02.02.01.03

Stile - Chicago Fifteenth Edition

Tontchev, Nikolay, and Zoran Čekerevac. "Multicriteria decision support-approach and application in the field of materials science." Edited by Zoran Čekerevac. MEST Journal (MEST) 2, no. 1 (01 2014): 18-29.

Style - GOST Name Sort:

Tontchev Nikolay and Čekerevac Zoran Multicriteria decision support-approach and application in the field of materials science [Journal] // MEST Journal / ed. Čekerevac Zoran. - Belgrade : MEST, 01 15, 2014. - 1 : Vol. 2. - pp. 18-29. - ISSN 2334-7058 (Online); ISSN 2334-7171.

Style - Harvard Anglia:

Tontchev, N. \& Čekerevac, Z., 2014. Multicriteria decision support-approach and application in the field of materials science. MEST Journal, 15 01, 2(1), pp. 18-29.

Style - ISO 690 Numerical Reference:

Multicriteria decision support-approach and application in the field of materials science. Tontchev, Nikolay and Čekerevac, Zoran. [ed.] Zoran Čekerevac. 1, Belgrade : MEST, 01 15, 2014, MEST Journal, Vol. 2, pp. 18-29. ISSN 2334-7058 (Online); ISSN 2334-7171. 